\title{
Analysis of the influence of RDE test data processing methods on the emission results of China 6 light duty vehicles
}

\author{
Zhihong Wang ${ }^{12}$, Penghui $\mathrm{Wu}^{12}$, Nenghui $\mathrm{Yu}^{1,2}$, Yuanjun Zhang ${ }^{3, *}$, and Zhijun $\mathrm{Wang}^{3}$ \\ ${ }^{1}$ Hubei Key Laboratory of Advanced Technology for Automotive Components (Wuhan University of \\ Technology), Wuhan, Hubei 430070, China \\ ${ }^{2}$ Hubei Collaborative Innovation Center for Automotive Components Technology, Wuhan, Hubei \\ 430070, China \\ ${ }^{3}$ Xiangfan Da An Automobile Test Center, Xiangyang, Hubei 441004, China
}

Keywords: China 6 light duty vehicle, $\mathrm{CO}_{2}$ moving averaging window method, power binning method, RDE.

\begin{abstract}
The $\mathrm{CO}_{2}$ moving average window(MAW) method is used to process RDE (real drive emissions) emissions data in China 6 light duty vehicle emissions regulations, while the Euro 6 light duty vehicle emission regulations allow to use both of MAW and power binning(PB) method to deal with RDE emission data. In order to study the difference between the two data processing methods and analyze the differences in the emission results, 10 different types of light duty vehicles are conducted RDE test with PEMS (portable emissions measurement system), and the test data are processed by the two methods separately. The results show that there is a little difference between MAW and PB, while both of them can satisfy the vehicle emission assessment. The $\mathrm{PB}$ method calculates the emission factors higher than the MAW method. After removing the cold start and idle condition data, the results of PB is similar to MAW. Besides, reducing the average speed limit of urban working conditions in PB has a greater impact on the urban driving condition emission factor, but less on the whole cycle emission factor.
\end{abstract}

\section{Introduction}

The car ownership increased from 125.7 million to 231.2 million with an average annual growth of $13.0 \%$ from 2013 to 2018 in China. Respectively, the emissions of CO, HC, NOx and PM were 28.6078 million tons, 3.2676 million tons, 5.2125 million tons and 422100 tons, accounting for $92.6 \%, 88.6 \%, 92.7 \%$ and $95.5 \%$ of vehicle emissions. Ecological environment problems caused by automobile exhaust emissions are increasingly serious, which affect human health and ecological environment quality severely ${ }^{[2-4]}$.

Because of the large difference of the emission between laboratory test and real road driving [5-8], major regions in the world have implemented increasingly stringent regulations

\footnotetext{
* Corresponding author: zhangyuanjun@nast.com.cn
} 
to control the real drive emissions (RDE). Europe has fully implemented Euro 6C emission regulations in 2017, and China's six light duty vehicle emission standards will be implemented on July 1, 2020. Both emission regulations require RDE test and stipulate the limits of pollutants ${ }^{[9]}$. In the Euro 6 emission regulation, two different processing methods can be used for $\mathrm{RDE}$ test data: power binning(PB) and $\mathrm{CO} 2$ moving average window(MAW $)^{[10-12]}$. However, only MAW is used to process RDE test data in China's six emission regulations.

This paper selects 10 different types of light duty vehicles and uses PEMS to carry out the RDE test to study the difference of test results between the two methods. Both methods were used to process the test data and then compared.

\section{Test equipment and methods}

\subsection{Vehicles}

A total of 10 light duty vehicles met the China 6 emission regulations were selected for this test with the labels of A1, A2, B1, B2, C1, C2, D1, D2, E1 and E2, including two sedans, two SUVs, two MPV trucks, two micro trucks and two pickups. The vehicle characteristics are shown in Table 1.

Table 1. Vehicle characteristics.

\begin{tabular}{|c|c|c|c|c|c|c|c|}
\hline $\begin{array}{l}\text { Vehicle } \\
\text { ID }\end{array}$ & Model & $\begin{array}{c}\text { Engine } \\
\text { mass }(\mathrm{kg})\end{array}$ & $\begin{array}{c}\text { Engine } \\
\text { power }(\mathrm{kW})\end{array}$ & $\begin{array}{c}\text { Engine } \\
\text { capacity }(\mathrm{L})\end{array}$ & $\begin{array}{l}\text { Fuel } \\
\text { type }\end{array}$ & $\begin{array}{l}\text { Drive } \\
\text { mode }\end{array}$ & $\begin{array}{c}\text { Regulation } \\
\text { Stages }\end{array}$ \\
\hline A1 & Sedan & 1250 & 102 & 1.6 & Gasoline & $4 \times 2$ & China 6 \\
\hline A2 & Sedan & 1300 & 90 & 1.5 & Gasoline & $4 \times 2$ & China 6 \\
\hline B1 & SUV & 1650 & 133 & 1.5 & Gasoline & $4 \times 2$ & China 6 \\
\hline B2 & SUV & 1200 & 85 & 1.5 & Gasoline & $4 \times 2$ & China 6 \\
\hline $\mathrm{C} 1$ & MPV & 1500 & 108 & 1.5 & Gasoline & $4 \times 2$ & China 6 \\
\hline $\mathrm{C} 2$ & MPV & 2840 & 155 & 2.0 & Gasoline & $4 \times 2$ & China 6 \\
\hline D1 & $\begin{array}{l}\text { Micro } \\
\text { truck }\end{array}$ & 1530 & 73 & 1.5 & Gasoline & $4 \times 2$ & China 6 \\
\hline D2 & $\begin{array}{l}\text { Micro } \\
\text { truck }\end{array}$ & 1410 & 82 & 1.5 & Gasoline & $4 \times 2$ & China 6 \\
\hline E1 & Pickup & 2000 & 110 & 1.9 & Diesel & $4 \times 2$ & China 6 \\
\hline E2 & Pickup & 1950 & 110 & 1.9 & Diesel & $4 \times 4$ & China 6 \\
\hline
\end{tabular}

\subsection{Equipment}

Since there are no requirements for total hydrocarbon (THC) and total particle mass (CPM) emission values in the China 6 light duty vehicle emission regulations, they are not measured in this test. Sensor LDV is selected as the test equipment, which is mainly composed of power supply communication system, gas analysis system $\left(\mathrm{CO}, \mathrm{CO}_{2}, \mathrm{NO}\right.$ and $\left.\mathrm{NO}_{2}\right)$, particle number analysis system (PN), exhaust flowmeter, OBD reading module, GPS module, environmental weather station, master control notebook computer, etc. The main emission measurement principle and measurement accuracy are shown in Table 2. Its installation diagram is shown in Figure 1. 
Table 2. Sensor LDV performance parameters.

\begin{tabular}{|c|c|c|c|c|}
\hline Pollutant & Measurement & $\begin{array}{l}\text { Resolution/measurement } \\
\text { range }\end{array}$ & Range & Response time \\
\hline $\mathrm{CO}_{2}$ & NDIR & $0.01 \%$ & $0-18 \%$ & $\leqslant 10 \mathrm{~s}$ \\
\hline $\mathrm{CO}$ & NDIR & $10 \mathrm{ppm}$ & $0-8 \%$ & $\leqslant 10 \mathrm{~s}$ \\
\hline $\mathrm{O}_{2}$ & $\begin{array}{c}\text { Electrochemistry } \\
\text { analysis }\end{array}$ & $0.1 \%$ & $0-25 \%$ & $\leqslant 6 \mathrm{~s}$ \\
\hline NO & NDUV & $0.1 \mathrm{ppm}$ & $0-3000 \mathrm{ppm}$ & $\leqslant 10 \mathrm{~s}$ \\
\hline $\mathrm{NO}_{2}$ & NDUV & $0.1 \mathrm{ppm}$ & $0-1000 \mathrm{ppm}$ & $\leqslant 10 \mathrm{~s}$ \\
\hline PN & $\mathrm{CPC}$ & $23-2500 \mathrm{~nm}$ & $\begin{array}{l}0-10^{4} \\
\# / \mathrm{cm}^{3}\end{array}$ & $\leqslant 10 \mathrm{~s}$ \\
\hline
\end{tabular}

\subsection{Test method and test route}

The selected 10 vehicles are driven on the same route under urban, suburban and motorway conditions based on the RDE test requirements of China 6 emission regulations. The test requirements are shown in Table 3.

All vehicles are driven along the same route for reducing the impact of test sites. Test route starts at Benz Avenue in Xiangyang City, passing through urban, suburban and finished on the motorway sections. As shown in Figure 2, the data of RDE test route of a certain vehicle is recorded by GPS and displayed on Google Earth.

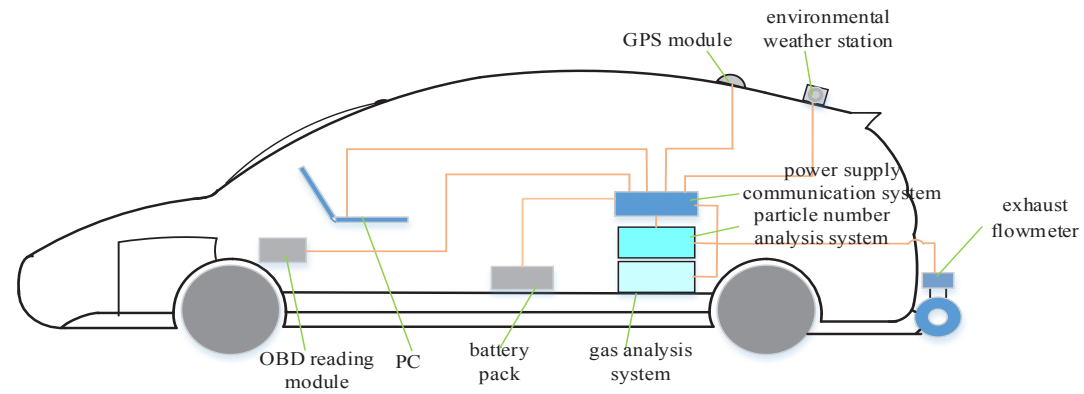

Fig. 1. Portable emissions measurement system(PEMS).

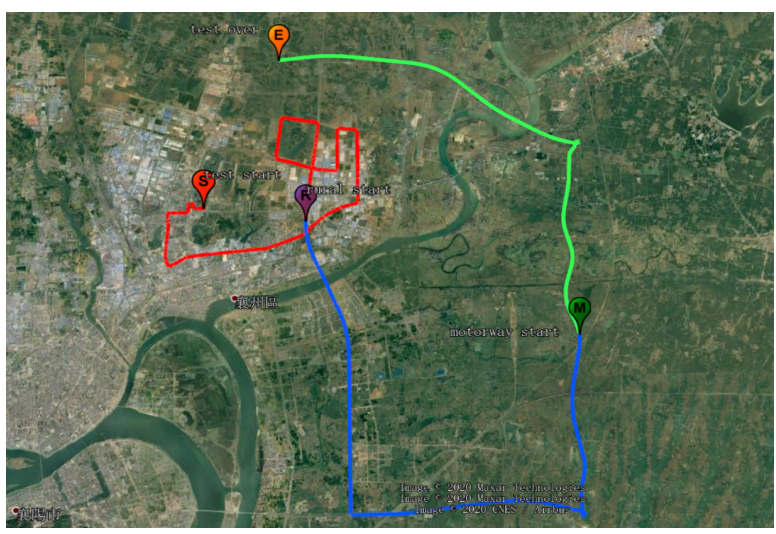

Fig. 2.A test route of RDE. 


\section{Introduction of $\mathrm{CO}_{2}$ moving average window method}

The $\mathrm{CO}_{2}$ moving average window method is to move and calculate the data from front to back (or from back to front) according to the sampling frequency after eliminating the abnormal RDE test data to divide the data into several subsets. A window is defined when the $\mathrm{CO}_{2}$ accumulation reaches half of the total $\mathrm{CO}_{2}$ emission of WLTC test in a subset. And then verify the integrity and normality of these windows to calculate the emissions of each pollutant.

Table 3. RDE test requirements for national VI light duty vehicles.

\begin{tabular}{|c|c|c|c|c|c|c|c|}
\hline $\begin{array}{c}\text { Conditi } \\
\text { on }\end{array}$ & Speed & $\begin{array}{c}\text { Milea } \\
\text { ge }\end{array}$ & $\begin{array}{l}\text { Percenta } \\
\text { ge of } \\
\text { mileage }\end{array}$ & Time & Altitude & $\begin{array}{c}\text { Temperatur } \\
\mathrm{e}\end{array}$ & Load \\
\hline Urban & $\begin{array}{c}\leq 60 \mathrm{~km} / \\
\mathrm{h}, \\
\text { average } \\
\text { speed : } \\
15- \\
40 \mathrm{~km} / \mathrm{h} \\
\text { (1) }\end{array}$ & $\begin{array}{c}\geq 16 \mathrm{k} \\
\mathrm{m}\end{array}$ & $\begin{array}{c}34 \% \pm 10 \\
\% \\
\text { and } \geq 29 \\
\%\end{array}$ & \multirow{3}{*}{$\begin{array}{c}\text { Total } \\
\text { time : } 9 \\
0- \\
120 \mathrm{mi} \\
\mathrm{n}\end{array}$} & $\begin{array}{l}\text { General } \\
\text { altitude } \leq 700 \mathrm{~m}^{(3)} \text {; } \\
\text { altitude difference }\end{array}$ & \multirow{3}{*}{$\begin{array}{l}\text { General } \\
\text { temperatur } \\
\mathrm{e}: 0-30^{\circ} \mathrm{C}^{(4)}\end{array}$} & \multirow{3}{*}{$\begin{array}{l}\leq 90 \% \\
\text { maxim } \\
\text { um } \\
\text { load }\end{array}$} \\
\hline $\begin{array}{l}\text { Suburb } \\
\text { an }\end{array}$ & $\begin{array}{c}60- \\
90 \mathrm{~km} / \mathrm{h}\end{array}$ & $\begin{array}{l}\geq 16 \mathrm{k} \\
\mathrm{m}\end{array}$ & $\begin{array}{c}33 \% \pm 10 \\
\%\end{array}$ & & $\begin{array}{c}\text { between starting } \\
\text { and terminal } \\
\text { point } \leq 100 \mathrm{~m} \text {; } \\
\text { cumulative positive } \\
\text { altitude } \\
\text { increment } \leq 1200 \mathrm{~m} / 1\end{array}$ & & \\
\hline $\begin{array}{c}\text { Motorw } \\
\text { ay }\end{array}$ & $\begin{array}{c}>90 \mathrm{~km} / \\
\mathrm{h} \text { and } \\
\leq 135 \mathrm{k} \\
\mathrm{m} / \mathrm{h}^{2}\end{array}$ & $\begin{array}{l}\geq 16 \mathrm{k} \\
\mathrm{m}\end{array}$ & $\begin{array}{c}33 \% \pm 10 \\
\%\end{array}$ & & $00 \mathrm{~km}$ & & \\
\hline
\end{tabular}

(1) Parking time in urban area (speed less than $1 \mathrm{~km} / \mathrm{h}$ ) should account for $6-30 \%$ of urban driving time.

(2) The driving time shall not exceed $3 \%$ of the motorway time when the vehicle speed exceeds $120 \mathrm{~km}$ / h; the vehicle speed shall cover $100-110 \mathrm{~km} / \mathrm{h}$, and the driving time when the speed is greater than $100 \mathrm{~km} / \mathrm{h}$ shall not be less than $5 \mathrm{~min}$; for M2 vehicles, if the speed is limited to $100 \mathrm{~km} / \mathrm{h}$, the speed shall cover $90-100 \mathrm{~km} / \mathrm{h}$, and the time when the speed is greater than $90 \mathrm{~km} / \mathrm{h}$ shall not be less than $5 \mathrm{~min}$.

(3) The general altitude is not higher than $700 \mathrm{~m}$; the extended altitude is $700-1300 \mathrm{~m}$; the further extended altitude is $1300-2400 \mathrm{~m}$.

(4) General temperature: $0-30^{\circ} \mathrm{C}$; the extended temperature: $-7-0^{\circ} \mathrm{C}$, or $30-35^{\circ} \mathrm{C}$.

\subsection{Abnormal data elimination}

The data of test equipment calibration, vehicle cold start, ground speed less than $1.0 \mathrm{~km} / \mathrm{h}$ and engine flameout should be eliminated based on the national VI regulation before processing $\mathrm{RDE}$ test data with $\mathrm{CO}_{2}$ moving average window method. The non-cold start condition is that the engine coolant temperature reaches $70{ }^{\circ} \mathrm{C}$ (or above) or the vehicle start time reaches 5 min or more. The cold start ends when one of the condition is met. 


\subsection{Moving average window}

The average window method is that the cumulative $\mathrm{CO}_{2}$ emission of $\mathrm{RDE}$ test data from one point forward or backward is exactly not less than half of $\mathrm{CO}_{2}$ emission of WLTC test cycle, as $\mathrm{M}_{\mathrm{CO}_{2} \text {,ref }}$, The formula is as follows:

$$
\mathrm{M}_{\mathrm{Co}_{2}}\left(t_{2, i}-\Delta t\right)-\mathrm{M}_{\mathrm{Co}_{2}}\left(t_{1, i}\right)<\mathrm{M}_{\mathrm{CO}_{2}, \mathrm{ref}} \leq \mathrm{M}_{\mathrm{Co}_{2}}\left(t_{2, i}\right)-\mathrm{M}_{\mathrm{co}_{2}}\left(t_{1, i}\right)
$$

$\mathrm{M}_{\mathrm{Co}_{2}}\left(t_{1, i}\right)$ : cumulative $\mathrm{CO}_{2}$ mass from test start to time ( $\left.\mathrm{t}_{1, \mathrm{j}}\right)$, unit: $\mathrm{g}$;

$\mathrm{M}_{\mathrm{Co}_{2}}\left(t_{2, i}\right)$ : cumulative $\mathrm{CO}_{2}$ mass from test start to time $\left(\mathrm{t}_{2, \mathrm{j}}\right)$, unit: $\mathrm{g}$;

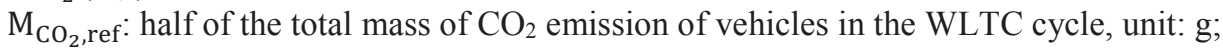

$\Delta \mathrm{t}$ : sampling frequency of equipment used in the test.

Regarding A1, $\mathrm{M}_{\mathrm{CO}_{2} \text {, ref }}=1452.24 \mathrm{~g}$ when under WLTC cycle. The RDE test data were divided into 3829 windows, and the 100th and 2500th windows were shown in the dotted box in Fig. 3. After the windows are divided by the instantaneous emission integral method, the pollutant emission value and average speed of each window can be calculated.

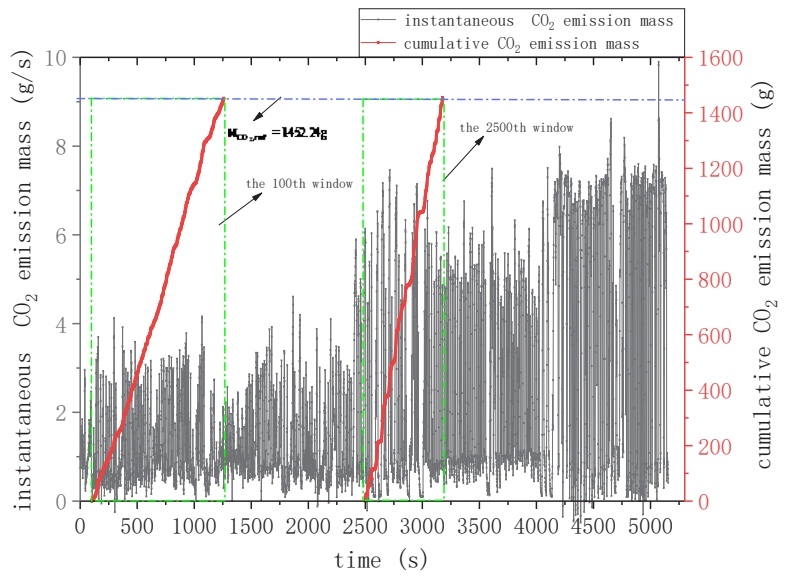

Fig. 3. Window division example of moving average window method for A1.

\subsection{Window evaluation and validation}

The integrity and normality of the divided windows are verified by $\mathrm{CO}_{2}$ characteristic curve. And the weighted coefficient of each pollutant emission is calculated quantitatively. Three reference points $\mathrm{P} 1, \mathrm{P} 2$ and $\mathrm{P} 3$ are needed to determine the $\mathrm{CO}_{2}$ characteristic curve, which correspond to the average speed of urban, high speed and super high speed section of WLTC cycle, and the weighted emission of $\mathrm{CO}_{2}$ at corresponding speed.

$\mathrm{P}_{1}\left(\overline{\mathrm{V}_{\mathrm{P}_{1}}}, \mathrm{M}_{\mathrm{CO}_{2}, \mathrm{~d}, \mathrm{P}_{1}}\right), \overline{v_{P_{1}}}=19 \mathrm{~km} / \mathrm{h}$, average speed of low speed section of WLTC cycle; $\mathrm{M}_{\mathrm{CO}_{2}, \mathrm{~d}, \mathrm{P}_{1}}$ represents 1.2 times of the results of vehicle $\mathrm{CO}_{2}$ emission in low speed section of WLTC cycle, unit: $\mathrm{g} / \mathrm{km}$.

$\mathrm{P}_{2}\left(\overline{\mathrm{V}_{2}}, \mathrm{M}_{\mathrm{CO}_{2}, \mathrm{~d}, \mathrm{P}_{2}}\right), \overline{v_{P_{2}}}=56.6 \mathrm{~km} / \mathrm{h}$, average speed of high speed section of WLTC cycle; $\mathrm{M}_{\mathrm{CO}_{2}, d, \mathrm{P}_{2}}$ represents 1.1 times of the results of vehicle $\mathrm{CO}_{2}$ emission in the high speed section of WLTC cycle, unit: $\mathrm{g} / \mathrm{km}$. 
$\mathrm{P}_{3}\left(\overline{\mathrm{V}_{\mathrm{P}_{3}}}, \mathrm{M}_{\mathrm{CO}_{2}, \mathrm{~d}, \mathrm{P}_{3}}\right), \overline{\mathrm{v}_{P_{3}}}=92.3 \mathrm{~km} / \mathrm{h}$, average speed of super high speed section of WLTC cycle; $\mathrm{M}_{\mathrm{CO}_{2}, \mathrm{~d}, \mathrm{P}_{3}}$ represents 1.05 times of the results of vehicle $\mathrm{CO} 2$ emission in the high speed section of WLTC cycle, unit: $\mathrm{g} / \mathrm{km}$.

$\mathrm{RDE}$ test is divided into urban window, suburban window and motorway window based on the average speed of windows. The average speed of each window is less than $45 \mathrm{~km} / \mathrm{h}$, $45-80 \mathrm{~km} / \mathrm{h}$ and $80-145 \mathrm{~km} / \mathrm{h}$.

The window integrity verification requires that the proportion of each window of urban, suburban and motorway sections should not be less than $15 \%$ of the total windows. The window normality verification requires that more than $50 \%$ of the urban, suburban and motorway window points fall within the first tolerance range $( \pm 25 \%)$ of the $\mathrm{CO}_{2}$ characteristic curve of the vehicle. If the minimum requirement of $50 \%$ is not met, the value of tol ${ }_{1}$ of characteristic curve shall be increased in steps of $1 \%$, but not more than $50 \%$.

For A1, points P1, P2 and P3 are calculated with the method described above, as shown in Table 4. The results show that the number of windows in urban, suburban and motorway sections are 1397,1435 and 879 , accounting for $37.68 \%, 38.62 \%$ and $23.71 \%$ of the total windows, which are all greater than the required value of $15 \%$. It can be judged that the RDE test is integral. Moreover, if all the window points fall within the upper and lower basic tolerance lines, then the test results are normal. The $\mathrm{CO}_{2}$ characteristic curve of $\mathrm{RDE}$ test is shown in Fig. 4.

Table 4. parameter of $\mathrm{P}_{1}, \mathrm{P}_{2}$ and $\mathrm{P}_{3}$ of $\mathrm{A} 1$.

\begin{tabular}{cccc}
\hline & $\mathrm{P}_{1}$ & $\mathrm{P}_{2}$ & $\mathrm{P}_{3}$ \\
\hline$\overline{v_{P}}(\mathrm{~km} / \mathrm{h})$ & 19 & 56.6 & 92.3 \\
$M_{\mathrm{CO}_{2}, d, P}$ & 176.75 & 101.67 & 132.96 \\
$(\mathrm{~g} / \mathrm{km})$ & & &
\end{tabular}

$$
(19,176.75) \quad(56.6,101.67) \quad(92.3,132.96))
$$

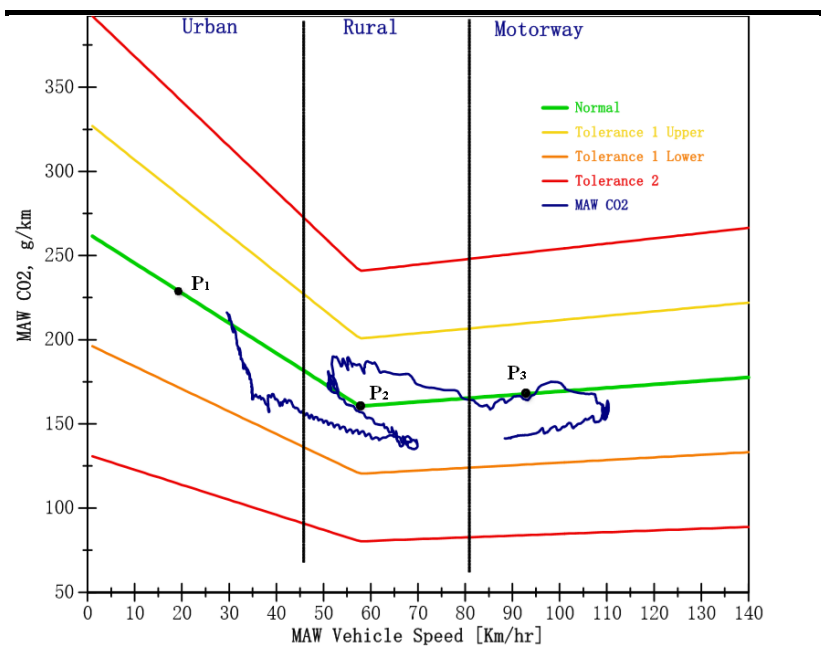

Fig. 4. $\mathrm{CO}_{2}$ characteristic curve of $\mathrm{A} 1$.

\subsection{Emission calculation}

The emission factors(EFs) of urban, suburban and motorway sections are calculated based on the positions of all windows in each section in the $\mathrm{CO}_{2}$ characteristic curve. The emission 
of whole cycle is determined by the weighted emission of each section and the mileage weighting coefficient of urban, suburban and motorway sections.

The formula for calculating the weighted average emission of urban, suburban and motorway sections is as follows:

$$
\mathrm{M}_{\text {gas, } \mathrm{d}, \mathrm{k}}=\frac{\sum\left(\mathrm{w}_{\mathrm{j}} \mathrm{M}_{\mathrm{gas}, \mathrm{d}, \mathrm{j}}\right)}{\sum\left(\mathrm{w}_{\mathrm{j}}\right)}, \mathrm{k}=\mathrm{u}, \mathrm{r}, \mathrm{m}
$$

$\mathrm{u}$ : Urban area; R: suburban; m:motorway; $\mathrm{w}_{\mathrm{j}}$ is the weighted coefficient of each window;

$\mathrm{M}_{\text {gas,d,k }}$ : Average emission factor of pollutants in j-th window, unit: $\mathrm{g} / \mathrm{km}$ or \# / km.

The value of weighting coefficient $\mathrm{w}_{\mathrm{j}}$ is determined by the position of coordinate point (formed by the average window speed and the average $\mathrm{CO}_{2}$ emission factor) falling into the $\mathrm{CO}_{2}$ characteristic curve. For A1, it can be seen from Figure 4 that the $\mathrm{CO}_{2}$ windows EFs are within the upper and lower basic tolerance lines, then $\mathrm{w}_{\mathrm{j}}=1$.

The whole cycle EFs are calculated based on the EFs and the weighted coefficients of urban, suburban and motorway sections :

$$
M_{\text {gas }, \mathrm{d}, \mathrm{t}}=1000 \cdot \frac{\mathrm{f}_{\mathrm{u}} \mathrm{M}_{\text {gas }, \mathrm{d}, \mathrm{u}}+\mathrm{f}_{\mathrm{r}} \mathrm{M}_{\text {gas }, \mathrm{d}, \mathrm{r}}+\mathrm{f}_{\mathrm{m}} \mathrm{M}_{\text {gas }, \mathrm{d}, \mathrm{m}}}{\left(\mathrm{f}_{\mathrm{u}}+\mathrm{f}_{r}+\mathrm{f}_{\mathrm{m}}\right)}
$$

$\mathrm{M}_{\text {gas,d,t }}$ : pollutant EFs of total journey, unit: $\mathrm{g} / \mathrm{km}$ or \# / km;

$M_{\text {gas,d,u }}, M_{\text {gas,d,r }}, M_{\text {gas,d,m }}$ : pollutant EFs of urban, suburban and motorway sections, unit: $\mathrm{g} / \mathrm{km}$ or \# / km;

$f_{u}, f_{r}$ and $f_{m}$ : weighted coefficients of urban, suburban and motorway sections, $f_{u}=0.34$, $\mathrm{f}_{\mathrm{r}}=0.3$ and $\mathrm{f}_{\mathrm{m}}=0.33$.

For A1, the calculated CO, NOx and PN EFs under various working conditions and the whole process are shown in Table 5.

Table 5. CO, NOx and PN emission factors of A1 in different stages and in the whole process.

\begin{tabular}{ccccc}
\hline Emission factor & Urban & Suburban & Motorway & Whole cycle \\
\hline $\mathrm{CO}_{2}(\mathrm{mg} / \mathrm{km})$ & 186.00 & 128.46 & 152.02 & 155.27 \\
$\mathrm{CO}(\mathrm{mg} / \mathrm{km})$ & 376.82 & 345.23 & 354.42 & 358.67 \\
$\mathrm{NOx}(\mathrm{mg} / \mathrm{km})$ & 3.37 & 2.55 & 0.45 & 1.94 \\
$\mathrm{PN}(\# / \mathrm{km})$ & $4.1 \mathrm{E}+11$ & $1.6 \mathrm{E}+11$ & $9.7 \mathrm{E}+10$ & $2.3 \mathrm{E}+11$ \\
\hline
\end{tabular}

\section{Introduction of power binning method}

Power binning method(PB) is another method to process the data of RDE test of European light duty vehicles. It calculates the function of wheel side power and $\mathrm{CO}_{2}$ emission based on WLTC cycle, estimates vehicle wheel side power according to $\mathrm{CO}_{2}$ emission per second in RDE test, and then classifies power level based on approved power and normalized standard power frequency distribution table of WLTC cycle. Finally, the data are grouped into moving average groups to calculate urban and total travel emission factors ${ }^{[13-15]}$.

\subsection{Wheel side power calculation and Veline}

According to vehicle dynamics, the wheel side power $\mathrm{P}_{\mathrm{w}, \mathrm{i}}$ of the WLTC test vehicle is the sum of the power of vehicle to overcome the air resistance, the wheel rolling resistance relative to the ground and the acceleration of the vehicle. The calculation formula of wheel side power per second of vehicle under WLTC cycle is as follows: 


$$
\mathrm{P}_{\mathrm{w}, \mathrm{i}}=\frac{\mathrm{v}_{\mathrm{i}} \cdot\left(\mathrm{f}_{0}+\mathrm{f}_{1} \cdot \mathrm{v}_{\mathrm{i}}+\mathrm{f}_{2} \cdot \mathrm{v}_{\mathrm{i}}^{2}+\mathrm{TM} \cdot \mathrm{a}_{\mathrm{i}} \cdot \mathrm{kr}\right)}{3.6 \times 1000}
$$

$\mathrm{f}_{0}, \mathrm{f}_{1}, \mathrm{f}_{2}$ : load coefficient set by WLTC test ${ }^{[9,16]}$;

TM: reference mass of vehicle in WLTC test, unit: $\mathrm{kg}$;

$\mathrm{v}_{\mathrm{i}}$ : vehicle speed at i second, unit: $\mathrm{km} / \mathrm{h}$;

$\mathrm{a}_{\mathrm{i}}$ : vehicle acceleration at I second, unit: $\mathrm{m} / \mathrm{s}^{2}$;

$\mathrm{kr}$ : inertia resistance of transmission system during acceleration, set as 1.03.

Therefore, the wheel side power should have a minimum value considering that the power required by the vehicle to overcome the external resistance can not be truly represented when the vehicle is braking. The towing power $\mathrm{P}_{\text {drag }}$ is defined as -0.04 times of the rated power of the vehicle $\mathrm{P}_{\text {rated. }}$

$$
P_{\text {drag }}=-0.04 P_{\text {rated }}
$$

When processing WLTC data, if the wheel side power calculated by formula 4 is less than the vehicle towing power $\left(\mathrm{P}_{\mathrm{w}, \mathrm{i}}<\mathrm{P}_{\mathrm{drag}}\right)$, then:

$$
\mathrm{P}_{\mathrm{w}, \mathrm{i}}=\mathrm{P}_{\mathrm{drag}}
$$

The average $\mathrm{CO}_{2}$ emission and wheel side power of each speed segment are calculated based on the four speed segments of low speed, medium speed, high speed and super high speed of WLTC cycle, and the Veline is obtained by linear regression. For A1, the relevant parameters are shown in Table 6 . The Veline line is obtained by linear regression, as shown in Figure 5.

Table 6. Parameters of wheel side power calculation of A1.

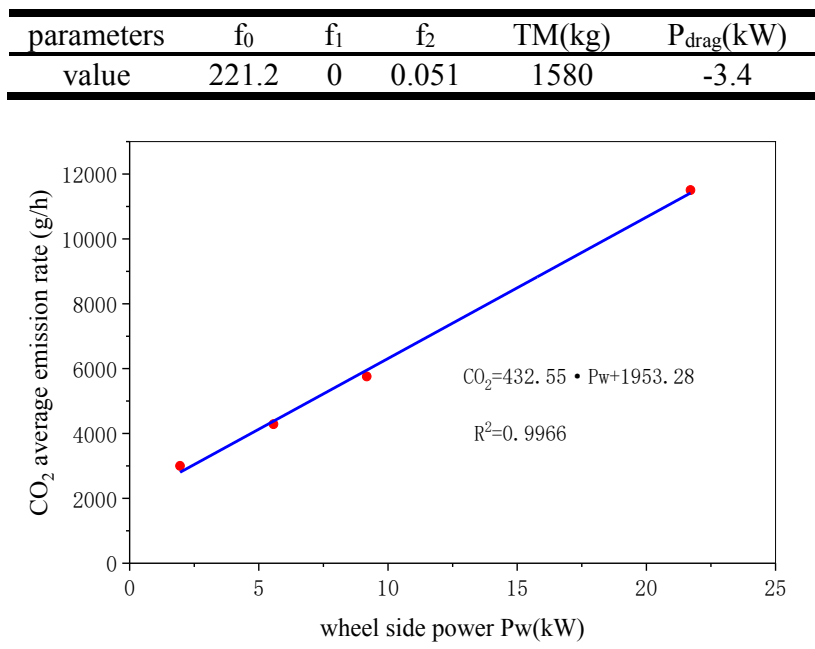

Fig. 5.Veline of A1.

The instantaneous wheel side power $\mathrm{P}_{\mathrm{w}, \mathrm{i}}$ of the test vehicle can be directly estimated from $\mathrm{CO}_{2}$ i of the measured vehicle through Veline in RDE test. But if $\mathrm{v}_{\mathrm{i}}<0.5 \mathrm{~m} / \mathrm{s}$ and $\mathrm{a}_{\mathrm{i}}<0$, then $\mathrm{P}_{\mathrm{W}, \mathrm{i}}=0$; if the instantaneous $\mathrm{CO}_{2}$ emission is less than half of the intercept of Veline, $\mathrm{P}_{\mathrm{W}, \mathrm{i}}=$ $\mathrm{P}_{\text {drag. }}$

\subsection{Power binning}

The average value of test data is moved back three seconds to reduce the inaccuracy of calculating instantaneous wheel side power caused by timing error between measuring 
equipment. Hence, the data in the first second is the average value of the original data in the first three seconds, the data in the second second is the average value of the original data in 2-4 seconds, and so on. The instantaneous wheel side power calculated after 3 seconds translation is normalized by the actual wheel side power $\mathrm{P}_{\text {drive }}$ under the reference condition. The actual wheel side power calculation under the reference condition is shown in formula 7:

$$
\mathrm{P}_{\text {drive }}=\frac{\mathrm{v}_{\text {ref }} \cdot\left(\mathrm{f}_{0}+\mathrm{f}_{1} \cdot \mathrm{v}_{\mathrm{i}}+\mathrm{f}_{2} \cdot \mathrm{v}_{\text {ref }}{ }^{2}+\mathrm{TM}_{\mathrm{NEDC}} \cdot \mathrm{a}_{\text {ref }}\right)}{3.6 \times 1000}
$$

$\mathrm{f}_{0}, \mathrm{f}_{1}, \mathrm{f}_{2}$ :load factor set during WLTC test;

$\mathrm{TM}_{\mathrm{NEDC}}$ : Inertia level in vehicle type approval test, unit: $\mathrm{kg}$;

$\mathrm{V}_{\text {iref }}=70 \mathrm{~km} / \mathrm{h}$ : reference speed of $\mathrm{P}_{\text {drive; }}$;

$\mathrm{a}_{\mathrm{ref}}=0.45 \mathrm{~m} / \mathrm{s}^{2}$ :reference acceleration.

The product of normalized standard power $\mathrm{P}_{\mathrm{c}, \text { nom,j }}$ and actual wheel side power $\mathrm{P}_{\text {drive }}$ under reference condition is the upper and lower limit of each wheel side power segment, which is divided into 9 groups, as shown in Table 7.

The RDE test data of vehicles are affected by many factors. It is not possible to cover all nine segments after grouping the power bins of each vehicle. However, the highest power bin of each vehicle must contain a power group of $0.9 \mathrm{P}_{\text {rated. }}$. And all the time portions beyond the highest group should be added to the highest group. Calculate the three second average instantaneous wheel side power from RDE test data. All data points with an average speed of less than $60 \mathrm{~km} / \mathrm{h}$ in 3 seconds and data points of the whole journey are allocated to relevant power bins by power. Thus, the power binning is preliminarily completed.

Table 7. Distribution of normalized standard power frequency

\begin{tabular}{c|c|c|cc}
\hline \multirow{2}{*}{ Power bins } & \multicolumn{2}{|c|}{$\mathrm{P}_{\mathrm{c}, \text { nom }, \mathrm{j}}[-]$} & Urban & Total \\
\cline { 2 - 5 } & \multicolumn{2}{|c|}{ from $>$} & to $\leqslant$ & \multicolumn{2}{c}{ Time percentage } \\
\hline 1 & & -0.1 & $21.9700 \%$ & $18.5600 \%$ \\
2 & -0.1 & 0.1 & $28.7900 \%$ & $21.8580 \%$ \\
3 & 0.1 & 1.0 & $44.0000 \%$ & $43.4583 \%$ \\
4 & 1.0 & 1.9 & $4.7400 \%$ & $13.2690 \%$ \\
5 & 1.9 & 2.8 & $0.4500 \%$ & $2.3767 \%$ \\
6 & 2.8 & 3.7 & $0.0450 \%$ & $0.4232 \%$ \\
7 & 3.7 & 4.6 & $0.0040 \%$ & $0.0511 \%$ \\
8 & 4.6 & 5.5 & $0.0004 \%$ & $0.0024 \%$ \\
9 & 5.5 & & $0.0003 \%$ & $0.0003 \%$ \\
\hline
\end{tabular}

\subsection{Normality check of power distribution}

A valid RDE test must meet the time share requirements of each power bin in Table 8 after binning the power. To ensure sufficient samples, the minimum number of power bins including $90 \%$ rated power and below shall not be less than 5 . At least 5 numbers are needed in the $5^{\text {th }}$ bin and below in urban journey. The average emission of bins should be set to 0 when numbers in bins beyond $5^{\text {th }}$ is less than 5 .

Regarding A1, the actual wheel side power $\mathrm{P}_{\text {drive }}$ is $22.18 \mathrm{~kW}$ under the reference working condition. And the time portion of the wheel side power bins is shown in Table 9, which has passed the normality verification.

Table 8. Requirement of time proportion in each power bin in effective experiment.

\begin{tabular}{llll} 
Power bin & $\mathrm{P}_{\mathrm{c}, \mathrm{nom}, \mathrm{j}}[-]$ & Total & Urban \\
\hline
\end{tabular}




\begin{tabular}{ccccccc}
\hline from $>$ & to $\leqslant$ & $\begin{array}{c}\text { Lower } \\
\text { limit }\end{array}$ & $\begin{array}{c}\text { Upper } \\
\text { limit }\end{array}$ & $\begin{array}{c}\text { Lower } \\
\text { limit }\end{array}$ & $\begin{array}{c}\text { Upper } \\
\text { limit }\end{array}$ \\
\hline Sum1+2 & & 0.1 & $15 \%$ & $60 \%$ & $5 \%$ & $60 \%$ \\
3 & 0.1 & 1.0 & $35 \%$ & $50 \%$ & $28 \%$ & $50 \%$ \\
4 & 1.0 & 1.9 & $7 \%$ & $25 \%$ & $0.7 \%$ & $25 \%$ \\
5 & 1.9 & 2.8 & $1.0 \%$ & $10 \%$ & $>5$ couts & $5 \%$ \\
6 & 2.8 & 3.7 & $>5$ counts & $2.5 \%$ & $0 \%$ & $2 \%$ \\
7 & 3.7 & 4.6 & $0 \%$ & $1.0 \%$ & $0 \%$ & $1 \%$ \\
8 & 4.6 & 5.5 & $0 \%$ & $0.5 \%$ & $0 \%$ & $0.5 \%$ \\
9 & 5.5 & & $0 \%$ & $0.25 \%$ & $0 \%$ & $0.25 \%$ \\
\hline
\end{tabular}

Table 9. Time portion of A1 wheel side power bins.

\begin{tabular}{c|c|c|c|c}
\hline \multirow{2}{*}{ Power bin } & \multicolumn{2}{|c|}{$\mathrm{P}_{\mathrm{c}, \text { nom, }}(\mathrm{kW})$} & \multicolumn{2}{c}{ Time portion (\%) } \\
\cline { 2 - 5 } & from $>$ & to $\leq$ & urban & total \\
\hline Sum1+2 & & 2.218 & $42.25 \%$ & $32.29 \%$ \\
3 & 2.218 & 22.18 & $48.71 \%$ & $45.68 \%$ \\
4 & 22.18 & 42.142 & $7.39 \%$ & $11.97 \%$ \\
5 & 42.142 & 62.104 & $1.65 \%$ & $9.90 \%$ \\
6 & 62.104 & 82.066 & 0 & $0.16 \%$ \\
7 & 82.066 & 102.028 & 0 & $0 \%$ \\
8 & 102.028 & 121.99 & 0 & $0 \%$ \\
9 & 121.99 & & 0 & $0 \%$ \\
\hline
\end{tabular}

\subsection{Calculation of emission factors}

Segment the power bins into 3 groups by three-second average moving speed to calculate urban and total travel emission factors. If the speed is less than $60 \mathrm{~km} / \mathrm{h}$, it is divided into urban area, and $60-90 \mathrm{~km} / \mathrm{h}$ is suburban, higher than $90 \mathrm{~km} / \mathrm{h}$ is motorway. Hence, the unit of $\mathrm{g} / \mathrm{s}$ is converted into $\mathrm{mg} / \mathrm{km}$.

$$
\begin{aligned}
\mathrm{M}_{\mathrm{w}, \text { gas }, \mathrm{d}} & =1000 \cdot \frac{\overline{\mathrm{m}}_{\text {gas }} \cdot 3600}{\overline{\mathrm{v}}} \\
\overline{\mathrm{m}}_{\text {gas }} & =\sum_{\mathrm{j}=2}^{9} \overline{\mathrm{m}}_{\text {gas }, \mathrm{j}} \times \mathrm{t}_{\mathrm{c}, \mathrm{j}} \\
\overline{\mathrm{v}} & =\sum_{\mathrm{j}=2}^{9} \overline{\mathrm{v}}_{\mathrm{j}} \times \mathrm{t}_{\mathrm{c}, \mathrm{j}}
\end{aligned}
$$

$\overline{\mathrm{V}}$ : average speed of each wheel side power bin, unit: $\mathrm{km} / \mathrm{h}$;

$t_{c, j}$ : time proportion of each wheel side power bin;

$\overline{\mathrm{m}}_{\text {gas,j }}$ : average value of pollutant emission of each wheel side power bin, unit: $\mathrm{g} / \mathrm{s}$.

The urban and total journey emission factors of A1 are shown in table 10.

Table 10. CO, NOx and PN emission factors of $A 1$ in urban and total journey.

\begin{tabular}{ccc}
\hline Emission & Urban & Total \\
\hline $\mathrm{CO}_{2}(\mathrm{~g} / \mathrm{km})$ & 184.87 & 154.85 \\
$\mathrm{CO}(\mathrm{mg} / \mathrm{km})$ & 374.35 & 357.58 \\
$\mathrm{NOx}(\mathrm{mg} / \mathrm{km})$ & 3.22 & 4.49 \\
$\mathrm{PN}(\# / \mathrm{km})$ & $3.5 \mathrm{E}+11$ & $2.1 \mathrm{E}+11$ \\
\hline
\end{tabular}

\section{Comparative analysis of data}

\subsection{Comparison of emission factors between two methods}


Ten light duty vehicles, including sedan, SUV, MPV, pickup and micro card, were conducted $\mathrm{RDE}$ test as requires. The test data were processed by $\mathrm{CO}_{2}$ moving average window method and power binning. As shown in Figure 6,the emission factors of different vehicles were compared.
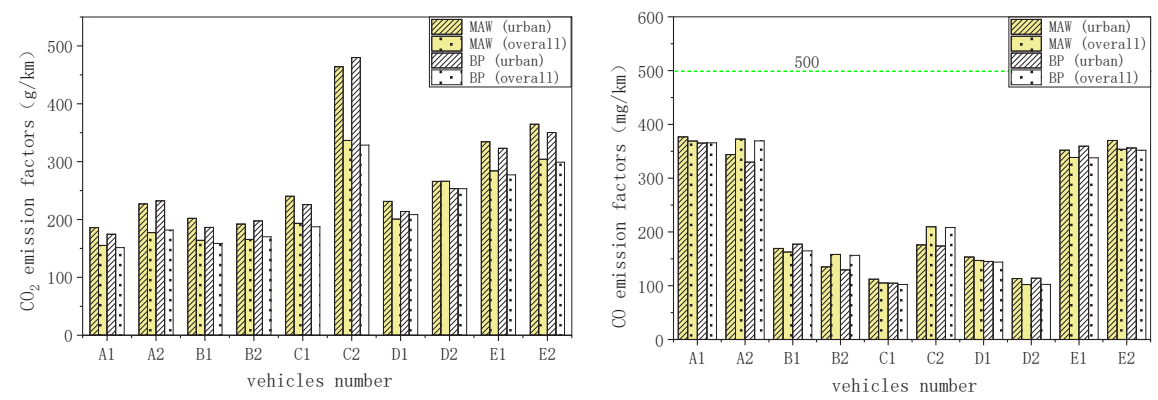

(a) $\mathrm{CO}_{2}$ emission factors comparison $\mathrm{CO}$ emission factors comparison
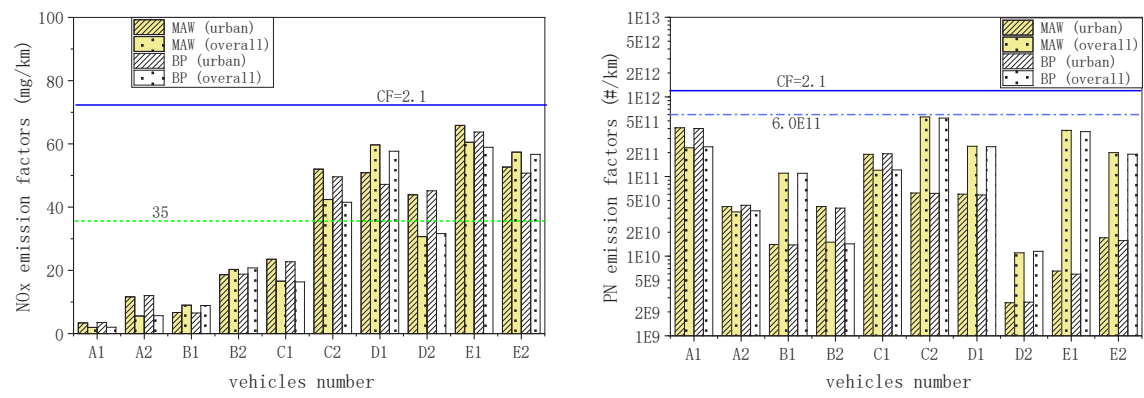

(b) NOx emission factors comparison

PN emission factors comparison

Fig. 6. The emission factors comparison of two data- processing methods.

All vehicle EFs meet the RDE emission regulations of China 6 light duty vehicles, while the results of $\mathrm{CO}_{2}, \mathrm{CO}, \mathrm{NOx}$ and $\mathrm{PN}$ are slightly different when using different method to process data. The EFs processed by PB are higher than those processed by MAW in both urban and whole cycle. In addition, the results of the two methods show that the urban EFs of most vehicles is higher than whole cycle and the difference of two methods in urban EFs is larger than whole cycle.

There are four differences as follows:

(1) Data elimination: The data of cold start, speed less than $1 \mathrm{~km} / \mathrm{h}$ and engine flameout shall be excluded based on the MAW of light duty vehicles in China 6 regulations. While PB in EU regulations does not require the elimination of such data;

(2)Division of urban cycle: Urban cycle is divided by average speed when calculating urban EFs in both methods.MAW divides windows with average window speed less than $45 \mathrm{~km} / \mathrm{h}$ into urban cycle, while power binning method divides power bin with three second moving average speed less than $60 \mathrm{~km} / \mathrm{h}$ into urban cycle;

(3)Urban EFs calculation method: The emission value of all windows must be multiplied by a weighting coefficient when MAW is used to calculate the EFs However, when PB is used to calculate the wheel side power, there is a large error, which has a great impact on the calculation result of EFs.

(4) Time span of data unit: The time span of data in one window of MAW ranges from hundreds of seconds to thousands of seconds, and vehicle driving cycle span is also large. While PB is to process data by three seconds moving average, which has strong real-time performance. 


\subsection{Comparison of urban EFs between two methods}

Due to the large difference between the results of two different data processing methods, the factors causing the urban EFs gap are studied in detail. Recalculate PB EFs that exclude the data of cold start and vehicle speed less than $1 \mathrm{~km} / \mathrm{h}$ as MAW requires and reduce the average speed of power bin from $60 \mathrm{~km} / \mathrm{h}$ to $45 \mathrm{~km} / \mathrm{h}$ under urban conditions. The results are shown in Fig. 7 .

It can be seen from the figure that after the data of cold start and vehicle speed less than $1 \mathrm{~km} / \mathrm{h}$ are eliminated by PB processing, the EFs of all test vehicles are decreased in varying degrees. But they are still higher than that of MAW. If the average speed limit of urban cycle in PB is reduced from $60 \mathrm{~km} / \mathrm{h}$ to $45 \mathrm{~km} / \mathrm{h}$, the calculated EFs may be lower or higher than the original EFs calculated by PB. According to figure 6, if urban EFs is higher (lower) than whole cycle EFs, urban EFs after deceleration is higher (lower) than original urban EFs. If urban EFs is higher (lower) than whole cycle EFs, it indicates that EFs of low-speed area is higher than (lower than) the high-speed area. Now the average speed of the urban area is reduced, which will lead to the increase (decrease) of urban EFs.

Besides, when the average speed limit of urban cycle is between 45 and $60 \mathrm{~km} / \mathrm{h}$, the influence on the whole EF is tiny. This is because PB is to calculate the instantaneous wheel side power. When calculating the whole EFs, the weighted factor is time proportion of each power group, so the EF calculated by the power binning method is less affected by the urban speed limit.
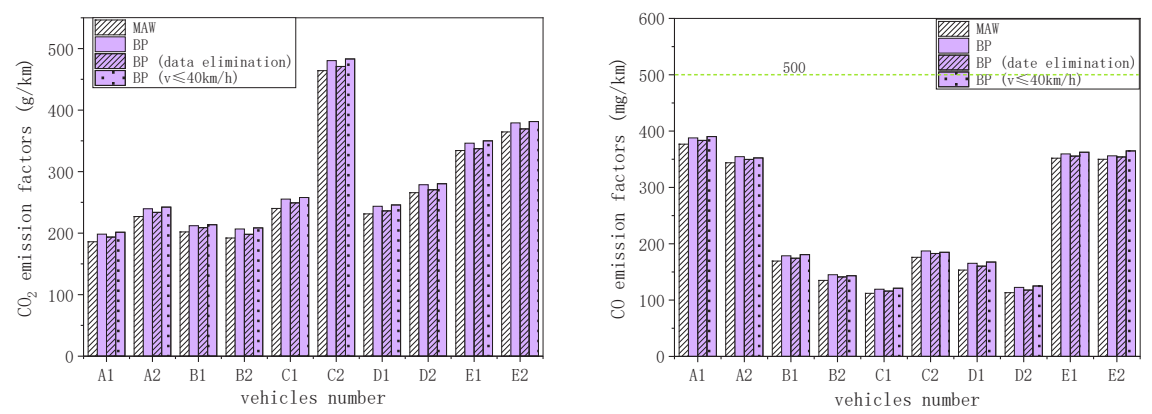

(a) urban $\mathrm{CO}_{2}$ emission factors comparison urban $\mathrm{CO}$ emission factors comparison
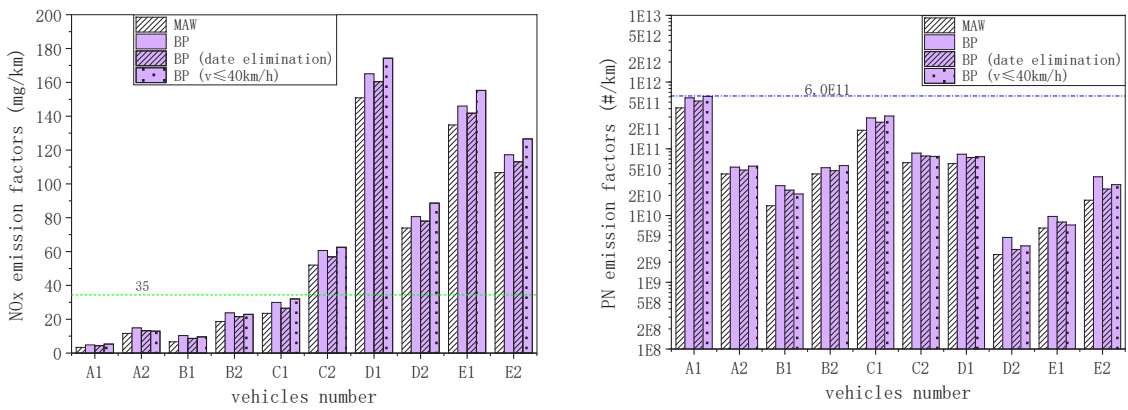

(b) urban NOx emission factors comparison

urban PN emission factors comparison

Fig.7. Comparison of emission factors obtained by eliminating data and reducing average speed.

\section{Conclusion}

(1)The EFs calculated by PB are slightly larger than those calculated by MAW with different calculation methods and data preprocessing. 
(2)The EFs calculated by PB is closer to the result of MAW after eliminating the data by MAW. It is found that the change trend of EFs of each vehicle in the urban cycle is consistent with the change trend of the ratio of original urban EFs and whole cycle EFs when the urban driving speed limit of power binning method is reduced to the same as that of $\mathrm{CO}_{2}$ moving average window method.

(3) Reducing the average speed limit of the urban cycle in the power binning method has a greater impact on the EFs of the urban cycle, but less on the whole cycle EFs.

4) Two different methods are used to process the data of RDE test for 10 light duty vehicles of different types. The results show that whole cycle EFs calculated by the two methods both meet the requirements of national VI light duty vehicle emission limits. While the EFs of some vehicles under urban conditions exceed the emission limits.

\section{References}

1. Ministry of environment and ecology of the people's Republic of China. Annual report on environmental management of motor vehicles in China [R]. Beijing: Ministry of environment and ecology of the people's Republic of China,2019.

2. Wang Zhangming. Study on emission characteristics and emission reduction scenarios of motor vehicles in Hefei [D]. Hefei: Hefei University of technology, 2017.

3. Fan wubo, Chen Junhui, Qian Jun, et al. Harm of vehicle exhaust on human health [J]. China environmental management, 2016, 8 (01): 110-113.

4. Institute H E. Traffic-related air pollution: acritical review of the literature on emission, exposure, and health effects[J]. Environment, 2010,131:409-444.

5. Zhu Qinggong, Yang Zhengjun, Wen Yi, et al. Comparative study on pollutant emissions of light vehicles under actual road driving and laboratory conditions [J]. Automotive engineering, 2017, 39 (10): 1125-1129, 1135.

6. A. Ramos, J. Muñoz, F. Andrés, et al. NOx emissions from diesel light duty vehicle tested under NEDC and real-word driving conditions[J]. Transportation Research Part D, 2018, (63): 37-48.

7. Georgios $\mathrm{T}$, Athanasios $\mathrm{D}$, Leonidas $\mathrm{N}$, et al. A study on the $\mathrm{CO}_{2}$ and $\mathrm{NOx}$ emissions performance of Euro 6 diesel vehicles under various chassis dynamometer and on-road conditions including latest regulatory provisions[J]. The Science of the total environment, 2019, (666): 337-346.

8. Merkisz, J, Pielecha, J, Bielaczyc, P, et al, Analysis of Emission Factors in RDE Tests as Well as in NEDC and WLTC Chassis Dynamometer Tests[J]. SAE Technical Paper, 2016-01-0980, 2016, doi:10.4271/2016-01-0980.

9. Ministry of ecology and environment of the people's Republic of China. GB/T 118352.6-2016 light duty vehicle emission limits and measurement methods (China phase 6) [S]. Beijing: China Standard Press, 2018.

10. Commission Regulation (EU) 2016/427 of 10 March 2016 amending Regulation (EC) No 692/2008 as regards emissions from light passenger and commercial vehicles (Euro 6). Off. J. Eur. Union L82, 1-98 European Commission.

11. Commission Regulation (EU) 2016/646, 2016b. Of 20 April 2016 amending Regulation (EC)No692/2008as regards emissions from light passenger and commercial vehicles (Euro 6). Off. J. Eur. Union L109, 1-22 European Commission.

12. Commission Regulation (EU) 2018/1832 of 5 November 2018 amending Directive 2007/46/EC of the European Parliament and of the Council, Commission Regulation (EC) No 692/2008 and Commission Regulation (EU) 2017/1151 for the purpose of 
improving the emission type approval tests and procedures for light passenger and commercial vehicles, including those for in-service conformity and real-driving emissions and introducing devices for monitoring the consumption of fuel and electric energy. Off. J. Eur. Union L301, 1-314 European Commission.

13. Zheng Sikai, Ge Yunshan, Chen Weicheng, et al. Influence of data processing methods on RDE test results [J]. Automotive engineering, 2018, v.40; no.287 (06): 25$30+44$.

14. Ma Zhicheng. Research on the characteristics of RDE of light vehicles [D]. Changchun: Jilin University, 2017.

15. Zhou Xiaoyan. Study on actual road driving emissions of light vehicles in China [D]. Beijing: Beijing University of technology, 2016.

16. Xin Yun, Luo Zemin, Huang Peng, et al. Road sliding resistance test based on national standard 6 for light vehicles [J]. Automotive practical technology, 2018, no.258 (03): 61-64. 